\title{
Convulsive Tic Disorder \\ Georges Gilles de la Tourette, Guinon and Grasset on the Phenomenology and Psychopathology of Gilles de la Tourette Syndrome
}

\author{
MARY M. ROBERTSON ${ }^{1}$ and DAN Z. REINSTEIN ${ }^{2}$ \\ ${ }^{1}$ Academic Department of Psychiatry, UCMSM, Middlesex Hospital, Mortimer Street, London \\ W1N 8AA, England \\ ${ }^{2}$ Whittington Hospital, London
}

\begin{abstract}
Gilles de la Tourette gained eponymous fame when he described nine cases of multiple tics, coprolalia and echolalia, and later he, Guinon and Grasset were the first to document the psychopathology of the Gilles de la Tourette syndrome. In particular, they noted the association between obsessional thoughts and behaviours and the tic disorder. In this paper we present the first English translations of their works referring to the psychopathology, comparing and contrasting their ideas to current concepts.
\end{abstract}

The first classic medical description of the Gilles de la Tourette Syndrome (GTS) was made in 1825 when Jean-Marc-Gasparel Itard reported the case of a French noblewoman, the Marquise de Dampierre, who had her first GTS symptoms at the age of 7 and finally died at the age of 85 years, still manifesting her symptoms. Georges Albert Edouard Brutus Gilles de la Tourette (1885) later described nine cases of the disorder which now bears his name, emphasizing the triad of multiple tics, coprolalia and echolalia.

The diagnostic criteria for the GTS have since altered, and include both multiple motor and one or more vocal tics (which usually occur many times a day, in bouts), the anatomical location, number, frequency, complexity and severity of which change over time. The symptoms appear before the age of 21 years (APA 1987 DSM111-R).

Guinon (1886) and Grasset (1890) were some of the first to comment on the psychopathology of GTS and it was in his paper of 1899 that Gilles de la Tourette first commented on the psychopathology of GTS patients when he noted the anxieties and phobias of his patients. In this paper we present the first English translations of these articles and compare and contrast the views of Gilles de la Tourette and his colleagues with present concepts.

Gilles de la Tourette in 1899 discussed thus: "The patient before you is 22. A few days ago she came to our consultation with her child and her sister; the latter's presence, as you will see, was most useful in helping us to clarify certain points in the diagnosis. She said she had come for help for a chorea. This seemed plausible, superficially at least, to judge from the muscular agitation of the face and the left-hand side of the body, which can be observed even now. 
"This is what she told us. She was somewhat sickly in childhood, and her constitution has remained rather fragile. At the age of 8 she was affected by involuntary muscular movements in her face, movements which soon spread to the upper limbs, hindering her as she took food to her mouth. Her parents then took her to hospital where chorea was diagnosed, and she was prescribed arsenic as a result. After about 2 months, this lack of muscular coordination--which had never been accompanied by fever and had not confined her to bed-abated, and the child was able to go back to school. Two years later, she had another attack which lasted a little longer. A year after that there was a third. This time, antipyrine was prescribed and served as a basis for treatment.

"However, the patient had not been cured of her disease and further periods of agitation occurred. She says she has undergone five or six attacks including the present one. All the doctors she has consulted over the last 14 years--and they are many, both in hospital and in town, and include distinguished men-unanimously diagnosed chorea and treated her with arsenic and antipyrine.

"Such, in essence, is the clinical history that the patient revealed to us herself, illustrating her account with involuntary muscular movements of the face and upper and lower limbs, particularly on the left-hand side.

"Well, to be quite frank, and with all due respect for the clinicians who diagnosed chorea and whose prescriptions she showed me, my first impression was that such a formal, unanimous decision needed revision. This is why:

"In the patient's summary to her condition, there was no mention of nervous attacks. What is more, examination revealed that the muscular spasms were in no way regular. It was therefore necessary to rule out, almost from the outset, rhythmic or, if you prefer, hysterical chorea.

"Now, in a 22-year-old patient, it is commonly accepted that chorea is hysterical chorea. I shall explain this at length later on. This is because true, or Sydenham's, chorea does not occur after puberty, that is after 14 or 15 years at the latest.

"Alternatively, this could be a case of chronic chorea-but this begins only rarely before the age of 15 or 16 , by which time the patient had already had several attacks, the earliest of these at age 8.

"Such were the thoughts that came to mind and drove me to ask several further questions. The elder sister was a great help in casting light on these.

"The first question was this: 'You tell me you have had five or six attacks of your illness, each one lasting from several weeks to a few months. Were you completely cured in between times?'

"The patient confirmed this, while the sister forced her to concede that from the age of 8 , even during the periods when she enjoyed very good health, she had nonetheless been subject to some spasms or involuntary movements, especially in the face, in the form of grimaces and blinking, and in the shoulders which were raised each in turn-these were well established facts. However, the patient, who probably hoped she had been completely cured, was keen to add that she had attached no importance to these spasms 
which did not hinder her either eating or drinking-unlike what had happened in her many bouts of illness.

"This observation - that the muscular spasms had in fact never completely disappeared from the age of 8-was most interesting to me. It led me to steer the history and examination towards an end which you will see becomes increasingly clear.

"In the short time our interview had lasted, I had heard the subject produce two or three times an expiratory laryngeal sound which coincided with the most pronounced involuntary movements of the face and upper left side of the body.

"I asked: 'Does this noise that you make with your mouth sometimes take the form of a syllable, or words, and do these words sometimes have a particular character?' The patient remained silent, but the sister broke in once more. 'Certainly, sir', she replied. 'My sister must forgive me, but I have to tell you: of the times you are speaking of-when she has a particularly violent spasm, my sister does not merely make an "Um" sound, or say "Oh" or "Ah"- she pronounces real words. Specifically, when her little boy, who is very nervous, irritates her, her spasms worsen, and she calls him "Pig" and "Bastard" [not a literal translation, but "salaud" is about as strong as "bastard" we think] and frequently includes the work "cambronne" in her exclamations. This is not invariable,' she continued 'and my sister will not accept this, but I must point out that her husband and I have often noticed these vulgar words which she has a distressing habit of uttering, even when she is in society.'

"I was not gripped - the chorea diagnosis which had been unanimous up until now-had to give way to one of 'convulsive tic disorder with coprolalia', a condition which I would like to discuss with you today.

"Before I expound on this, I should like to return to some of the significant peculiarities of the clinical history of the patient. Clearly, she comes from a neurotic background. Although the information about her parents, whom she hardly knew, is not very detailed, one of her sisters nevertheless is extremely nervous and very impressionable, probably neuraesthenic, and the other has been subject to bouts of hysteria. The patient herself presents the characteristics of a nervous temperament to an advanced degree: she has innumerable manias and she cannot get into bed without first checking several times that there is no one hidden under it. She has irrational apprehensions and groundless fears-all phenomena which plainly categorize her as unbalanced or, if you prefer, degenerate, to use a modern expression whose application is too broad in my view.

"Moreover, I must emphasize the fact that she can, through exercising will-power, stop these s,o-called choreic movements only for them to recommence a few moments later with greater intensity.

"As you see, it was not easy to formulate this diagnosis which I still have to justify - the sister's presence had been particularly useful in view of the patient's reticence which, very probably, had contributed to mislead the doctors who over the years had diagnosed chorea.

"I say 'over the last few years', for it is not very long since the convulsive 
tic disorder which this woman suffers from, in my opinion, had been given the place it deserves in medical wisdom.

"Perhaps I may remind you that in 1885, at the instigation of my teacher, $\mathrm{Mr}$ Charcot, I described for the first time a 'condition characterized by lack of motor coordination with echolalia and coprolalia' which was soon accepted by science under the more concise heading of 'convulsive tic disorder'.

"I was establishing in my work that the group of choreas, as it then was, was much too general, including as it did a condition which should be divorced from the group. This condition is one which, like Sydenham's chorea, with which it was always confused, begins at a very young age and evolves in the same incoordination of movements lasting quite some time. In contrast with chorea, however, the patient can temper and cause momentarily to cease his muscular spasms at will. Moreover, between attacks, a keen observer can always detect involuntary movements and once it is established the disease does not abate; it remains with the subject for life. This makes the prognosis radically different from true chorea. Moreover, the movements can be, and often are, accompanied both by echolalia - that is-repetition by the subject of a word or a sentence uttered in a loud voice, and also by coprolalia, a new term of my invention, whose meaning you will now understand.

"A year later, Mr Georges Guinon completed this symptomatology, noting that 'ticcers' almost always presented with a state of mental imbalance, characterized by innumerable phobias, arithmomania, agoraphobia - all signs of what we now call mental degeneration. At this time, $\mathrm{Mr}$ Charcot expounded in his 'Tuesday lessons' the symptomatology of the new disease and definitively confirmed the existence of the clinical condition which is convulsive tic disorder."

[Gilles de la Tourette here acknowledges the contribution of Guinon (1886) who was perhaps the first to comment on the obsessive-compulsive behaviours which are now recognized as an integral part of GTS-vide infra].

Guinon (1886) thus discussed several of his patients. "Mme J . . 60 years old ... a former cleaner at the Salpetrière ... suffered convulsions during childhood ... She had her menarche at 16 and was married at 16 years and 9 months. On her wedding night, her husband's approaches so terrified her that she threw him out of bed. The next morning, she was subject to hallucinations and heard voices, those of the people who had been at the wedding, laughing at her and singing. This happened only on that morning, and never recurred thereafter. She was committed to the Salpetrière, where she remained for 3 years. During this time she had bouts of mania (she remembers the term used to designate these attacks) during which at night she saw in her room a large cat which flew at her throat. These hallucinations disappeared as soon as light was brought. At the end of 3 years, she no longer had these bouts of mania except on rare occasions, under the influence of powerful emotions - such as when she learned of the death of her mother, who was killed in a neighbouring wing by another patient. In 
fact, she had been 13 months without an attack when the departure of the chief doctor, Monsieur Falret, at the same time as the news of the death of her sister, provoked further bouts of mania. She had two epileptic fits at this time which tempted them to put her in the epileptics' wing at St Anne, but they never recurred."

Guinon continues about the same patient: "The condition manifests itself in crises ... interspersed with periods of calm. When she presents with ... nothing unusual ... but it is not the same during the attacks. At these times, if you touch the patient suddenly, whether or not she sees the gesture, she springs up suddenly with a shout. It may be an inarticulate shout-'Ah!' or it may be accompanied by an obscene exclamation, such as 'Have you finished! Shit! Camel!' At the same time, she makes defensive movements which are often very violent, aimed at anybody who may be there. Thus, in hospital, she threatened Monsieur Charcot and, one day, in the bus, when the conductor brushed past her accidentally, she hit him violently. We saw her one day on the bus and it was a truly strange sight to see this poor woman leaping up if anyone so much as touched her... However, the worry which her state provokes has made her slightly hypochondriacal, and she is often overcome by suicidal feelings which she has in fact tried to act upon by attempting to poison herself with laudanum" (Guinon, 1886).

Guinon then describes his second case named Oll ... "aged $38 \ldots$ a railway worker ... admitted to the Salpetrière on the 19th of May 1885 ... Fourteen years ago, at the age of 29 he contracted syphilis. His life otherwise was pretty normal. The present phase of his illness started 5 months ago after an emotionally trying injustice (there had been promotion into his job of another employee who did not deserve it) ... involuntary movements were at first infrequent and only occurred when he thought of the injustice to which he was victim ... (this is followed by a description of his movement disorder) ... in addition to the phenomena I have just described, the patient presents tabetic symptoms, however without being afflicted by ataxia in his movements. For 5 or 6 years, he has suffered shooting pains in the lower limbs. Sometimes he has wet his bed. His pupils are unequal and an examination of the eye carried out by Monsieur P. revealed a lesion of the papilla of the optic nerve, known as tabetic papilla. Also, the rotulian reflexes had disappeared on both sides and there was considerable diminishment of genesic power. There was no change in sensitivity. His general state is satisfactory, his appetite is normal, his sleeping is good and at night the involuntary movements cease completely".

Guinon continues giving an excellent clinical description of obsessional behaviour with special reference to arithmomania: "The mental state of the patient is of great interest. He is excited, says he is going mad, and cries easily. He is very emotional and his emotions make his movements and grimaces increase. Thus, the sight of his wife and children whom he loves dearly trouble him so much that when he sees them his gestures and words become so frantic that he becomes almost incomprehensible. He is irritable and quarrelsome with people he does not know and even more so with those he is close to. Whereas before he preferred solitude, he now feels irresistibly 
drawn towards the society of others, although he knows that this will cause some imitation of a movement, or repetition of a phrase, and that this will make him appear ridiculous.

"But this is not all. There is also, in the patient's mental state, a certain number of phenomena which belong to the category of idées fixes, which can be likened to that singular mental disorder designated as folie du doute, delire de toucher, etc. He feels the need, almost every time he does something, to count up to a certain number before carrying out the action. And this number mania, which we may term arithmomania, is always with him. So, when he gets up in the morning, before he steps out of bed, he counts, and recounts, several times $1,2,3,4,5,6,7$. When he moves an object, he replaces it 5 or 7 times in the same place before moving it definitively. When he wants to open a door, he puts his hand near the handle and pretends to turn it 5 or 7 times before actually doing so. When he looks at himself in a mirror, before he can put down the mirror which he is holding in his hand, he has to look at himself 5 or 7 times without making a grimace, after which he stops, pleased with this little victory over himself. The fixed ideas are not confined to arithmomania, however. When he counts, he never stops at the figure six: he passes over it because he finds it particularly unpleasant. If he were given 6 francs, he says, he would rather only have 5 than be obliged to utter the word six. The same goes for all words which contain the sound ' $i$ ', although to a lesser extent. In another category of ideas, he feels obliged to go to such and such a place via a certain staircase. At Lariboisière, he went up one day to his room by another staircase, noticed his mistake on the way, forced himself to carry on, but once he had reached his destination he rapidly went down again in order to take the right staircase, the one which he is unfailingly driven to take to go up to his room. Since that time, these phenomena have increased a little and today (October 1885), the patient is obliged, before sitting down or walking or opening a door, not only to count up to 5 or 7 but to turn around 5 or 7 times or to walk around in a circle 5 or 7 times" (Guinon, 1886).

Guinon then discusses his third case named Bou ... Ernest, 22 years old who was admitted to the Salpetrière on the 9th of November 1885 . (He comments that there is no family history of mental illness.) "The start of the present illness was at age 8 or 9 . At this time, his father tells us, he would stop playing to carry out his tic, which consisted of scratching his anus 'like a dog' ... about a year ago ... (coprolalia started ... which is marked ...) ... He says he does not have a counting mania. But while we are examining him he is sitting at a table on which there is a magnet made of five sheets of metal, superimposed on each other. As I am writing, I notice that he is counting again and again 1, 2, 3, 4, 5 and moving the magnet about, moving it back and counting again. When there is a great number of objects on a table, he feels the need to move them about. He counts them and tries to place half of them on the right, the other half on the left. He does have number mania, then, but in fact it is not very accentuated".

Guinon continued: "Sometimes he is driven to look for a reason behind 
very ordinary things. Seeing a man pass in the street with a stick in his hand, he will wonder why he has a stick, and what use it is to him. But this never goes as far as being an obsession with him. He seeks an answer for a moment, and when he cannot solve his strange problem, he leaves it aside and no longer thinks of it.

"Sometimes he is overcome by obsessive memories. Thus, having heard a song the day before, he will torment himself trying to remember the tune or the words to the point of making himself unhappy for 2 or 3 days, or even more. Then it just passes: either he suddenly stops thinking about it, or he remembers his song alone, or with someone's help. He sometimes has obsessive ideas, fixed ideas. Thus, for example, he leaves his house to go shopping and, on the way, he gets the idea of going to a square or a boulevard a long way off to see if he will meet a friend. Then, he only thinks of that, forgets all that he has to do, and is satisfied only when he has fulfilled his irrational desire".

Guinon then discusses his fourth case, "patient X, aged 84, a dancer, came to consult Professor Charcot during November 1885. He was born in Rome. His mother was apparently always healthy. As for his father, he was a strange case. He was a ballet teacher and travelled the world, leading a most irregular life. He was said to have manias, for example, during a certain period of his life he could not sit on a chair without covering it with a cushion, for fear of catching some contagious disease. All his children are, according to the patient, very healthy, with no nervous complaints ..." (he then gives a description of the start of the movement disorder) (Guinon, 1886).

Guinon continued: "But it is since the present crisis, that is to say since November 1885, that the mental troubles developed considerably. Since this time, the patient has been obsessed by a series of fixed ideas which are very different. In spite of this he has always been quite lucid and perfectly aware of the absurdity of what he is imagining. At the beginning, he asked himself the most unlikely, disparate questions (folie du pourquoi), such as asking himself sometimes why he breathed, why his heart beat, sometimes why such and such a window that he was looking at had six panes and not five. $\mathrm{He}$ would drive himself mad trying to solve these insoluble, grotesque problems, to the extent that he felt himself to be in real pain. Then he was overtaken with the mania of moving and replacing every object he could touch. He never presented with folie du doute as such, or delire de toucher. In addition, he is markedly claustrophobic and cannot get into a closed car without being seized by a feeling of suffocation and pressure in his chest. He does not like to be alone in a room and at these times he suffers a marked increase in his involuntary movements and starts shouting. The people around him in fact hardly ever leave him alone, because, subject to the almost continual pain that these strange mental troubles cause him, and always absolutely aware of them, he often shows signs of wanting to jump out of the window.

"What makes him suffer especially is the feeling of fear which characterized the onset of his mental trouble and which is almost continuously present 
today. The patient seeks to explain his fear, he is afraid that he will never get well, of dying, of going mad. But in reality, this fear has no cause. He first feels (mental) pain and it is only later that he realizes that he is afraid.

"In the midst of this collection of symptoms, the general state remains satisfactory. Only his sleep is troubled by nightmares and he is slightly tired as a result. This is not to say that the order we have described is absolutely immutable and cannot be altered. It may very well be that one of the second-degree symptoms will appear first and even that, for a long time, if not always, it will be the only stigmata of the illness. These patients are essentially nevropaths, degenerates" ... whose tics, involuntary cries etc. are "merely episodic incidents".

Guinon then suggests that one can have the mental stigmata of GTS in the absence of motor and vocal tics, an interesting precursor to the suggestion that one of the phenotypes of the anticipated GTS gene(s) is obsessive-compulsive disorder (OCD), (vide infra). "It seems then that we are dealing with frustrated cases of convulsive tic disorder. Just as one can find cases of sclerosis en plaques characterized simply by slight spasmodic paraplegia with nystagmus, cases of Basedow's disease consisting solely of trembling and tachychardia, without goitre or exo-phthalmia, so one can find patients with convulsive tic disorder who do not present any involuntary movements, but only one of the other symptoms of the disease".

Guinon then discusses case 5 , " $\mathrm{Mr} \mathrm{M}$ who ... does not present with any form of exclamatory tic (echolalia, coprolalia tic) ... nor associated convulsive phenomena. $\mathrm{He}$ is a man who appears well in every sense and conducts his business with success. Apart from his spasmodic exclamations, no other nevropathic manifestation apart from his strange inclinations. He absolutely denies a suicide attempt which has been attributed to him on account of his second passion ...

"Monsieur Charcot drew our attention to the existence in our patients of a series of psychological phenomena which we have not found noted in other observations of this kind and which must, if we are to believe the few cases which we have studied, be quite frequent in the serious cases of tic disorder. These are fixed ideas. In an absolute sense, considered apart from the disease we are concerned with, the fixed ideas constitute, we know, an important chapter of mental pathology. We are aware that they can be extremely varied, and just to give a few examples, we will mention the folie du pourquoi, in which patients are irresistibly drawn to ask the reasons for absolutely insignificant things; the folie du doute, with delire du toucher, which differs slightly from fixed ideas in that it leads to genuinely fantastic ideas; arithmomania or number mania, and onomatomania, as recently described by Messieurs Charcot and Magnan. The field of fixed ideas is extremely broad and it will be easily understood that one may be exposed every day to new forms as research becomes more careful.

"Three of our patients (obs. II, III and IV) present very clear examples of fixed ideas. The first suffers from arithmomania, not because he is irresistibly led to make more or less complicated calculations, but because he 
is obliged to count up to a certain number on certain occasions. Before opening a door he must touch the handle $4,5,10$ or 20 times. The aversion he had for the number 6 , which he is careful never to utter, can equally be categorized as a fixed idea. It is the same with this singular mania that he has for moving and replacing in another order, or in another place, the objects he has in front of him. Besides these fixed ideas which are quite permanent with him, there have been temporary ones. For example, the idea that he must go to a certain place via a certain staircase, and not another one, to the extent that he had to retrace his steps one day when he inadvertently took the wrong route. This only happened during his stay at Lariboisière, and he has experienced nothing similar since.

"We find the same mania in the second patient for moving and replacing objects he sees. In addition, this patient has obsessional ideas, or fixed ideas, which make him forget everything which is not directly concerned with the momentary whim that he must satisfy, to the detriment of everything else.

"In the third patient, it is not a question of fixed ideas as such, but of a particular emotivity. This is a continual feeling of fear, of irrational panic which, even though it is not translated into physical acts, nevertheless has a profound effect on the character and the external habitus.

"It is not without interest to compare, as Monsieur Charcot has done in his lessons, these involuntary and automatic ideas which are to some extent convulsive, to the movements called tics which are also produced in an automatic, convulsive way. Buccola, in his important study of fixed ideas, compared the fixed idea, a true convulsion of the idea, to the spasmodic movement of a muscle. It is certain that these two phenomena: habitual involuntary movement, i.e. a tic, and fixed idea, are not very far removed from each other. When a spasmodic movement occurs in these patients, the excitement which provokes it comes from the cells of the cortex centres. Every movement of this kind is, as are voluntary movements, preceded by a motor representation of the same movement. And this is so true that the patient knows, at the precise moment when he is on the point of carrying out his tic, that it is going to happen, since he can in certain cases stop its external manifestation by an act of will. But in the general way of things, the will has lost this inhibitive power: the movement happens anyway. It is the same with the fixed idea, over which the will has no power. The phenomenon takes place just the same, in the cells of the cerebral cortex, and whether the obsessional thought has made too great an impression on the cells which are usually assigned to it, or the other thoughts are not strong enough to make an impression on their groups of cells, which is in effect the same thing, the cycle of association of ideas is interrupted and the passage from one idea to another can no longer take place: it is blocked by the fixed idea".

Guinon continues: "We demonstrated above how the involuntary emission of a sound or a word could be likened to an involuntary movement of some muscle of the face or of the limbs. Bringing the movement back to its point of departure, which is to say the motor representation which engenders it, we have just seen how close the tic is to the fixed idea. It is now easy to understand the link which joins all these phenomena: tics, involun- 
tary words and fixed ideas. All three seem to be part of the same family; the origin is the same, it is merely a question of degree.

1 Simple convulsive or impulsive motor representation, producing facial grimace or tic in the limbs.

2 More complex motor representation, leading to the emission of a sound or the pronunciation of a word or a phrase.

3 Ordinary convulsive or impulsive ideas, sometimes provoking quite complicated acts, such as counting or arranging objects on a table, sometimes limited to the mind without external signs, such as the feeling of perpetual fear without cause which we observed in one of our patients.

"To resume, we can give the name convulsive tic disorder to a condition which, in its gravest form, is accompanied by phenomena known as echolalia, echokinesia and coprolalia, as well as a particular mental state which is characterized primarily by the presence of fixed ideas. In its most benign form, it is only characterized by true tics, that is, facial grimaces or involuntary movements of the limbs, which are very frequent. All the phenomena which constitute the typical, full-blown form of tic disorder, can be found in isolated, so-called frustrated cases. In each case, whether it is complete or with just one of the signs we have mentioned, convulsive tic disorder is always the expression of a tare which is generally hereditary. It is not surprising that these phenomena which characterize the illness, and which seem so different at first sight, should be found together, constituting the same illness. For we believe we have shown that they are all from the same family and that we are quite justified in relating to each other the convulsive tic, the involuntary exclamation and the fixed idea" (Guinon, 1886).

Grasset (1890) also discusses the mental states of patients with GTS. "I point this out to you, because this phenomenon begins to enter into a new group of symptoms, which we will now discuss, the stigmates psychiques of the maladie des tics ... This is a new trait to note in our patient's casehistory, and an important one, although it is a negative sign: it is the total absence, despite the most detailed research, of psychological stigmata. The general rule is to find these stigmata in analogous cases.

"How may we understand and research psychological stigmata?

"We understand by this word a collection of signs, variable in aspect, which seem to prove that the mental state of the subject is not entirely normal.

"The psychological troubles in question can be very slight, and one should not think that in forcing the analogy, all those who present some of these stigmata are madmen who should be locked up; if that were the criterion, then a very small minority of the population would remain free.

"Thus we note, among these stigmata, all that the layman would call manias, which we propose to designate under the more scientific name of psychological tics. These are actually diminutives of the fixed, or obsessional idea.

"Many of you know, through having observed them in yourselves or in those immediately around you, the lower degrees of this obsession; you may 
have realized that it is compatible with a healthy mental state, or, at least, one considered healthy.

"Although it is disagreeable to be personally subjected to scrutiny, I can give you, as an example, an example of an obsession to which I have long been subject: I could not get on a train without feeling irresistibly driven to divide the figure representing the number of the train by the number of the compartment. How many people feel obliged to count, when they pass such and such a house, the number of windows, or bars on the windows, and are only calm once they have accomplished this calculation!"

Grasset discusses a patient and highlights her concern with symmetry or "evening up" which is so characteristic of GTS patients today. "I know a person, in all other respects utterly reasonable, who, when she steps on an uneven stone, feels forced to find one for the other foot to step on. Similarly, when she touches marble or some other cold object with her hand, she is constrained to give the other hand the same sensation. Other people have a mania, wherever they may be, for symmetry. They cannot stop themselves ordering, according to their mania, objects which have been badly or asymmetrically arranged.

"A dedicated reader will only be calm once he has carefully erased a full stop which an inattentive editor has left on the page of his book, and this he will do without regard for the continuity of his reading.

"Nowadays obsession is a phenomenon which is documented and analyzed. Its relationship, in certain cases, to mental illness, is well known and even novelists, those faithful pointers of reality, are unafraid to describe it in their works, in scientific terms. Hector Malot's last novel, Mother, relates, in touching scene which I would like to read to you, the overwhelming demands of obsession.

"It is in any case important to know the principal forms of these psychological stigmata, in order to be able to recognize them in ticcers." Guinon's article gives a good summary of these.

"Firstly, there is obsession with a largely futile idea. Certain people, for example, spend a whole day trying to remember a tune. A very common, distressing obsession consists in a feeling of indescribable fear which may strike at any time. They (the patients), Guinon says, are continually afraid of everything and nothing at the same time-the fear of dying, of going mad, of losing consciousness. In reality, this terror is utterly groundless. It is a kind of distress which constrains the patients and which they try to explain. At other times, this continual feeling of fear takes on a physical aspect, and these unfortunate people are afraid of killing themselves when they hold a knife, for example, or of drowning themselves if they are by a river. In the same class of ideas, we find agoraphobia, topophobia and claustrophobia. There are even people who are afraid of being afraid.

"In the same class of ideas, but in another form, we find the 'folie du pourquoi', not asking usefully or reasonably the question 'why', but asking it without reason. The patients are irresistibly driven to ask themselves the reason for quite ordinary things: why such and such an individual that they meet is carrying a stick, why a window has six panes, for example. 
"Also, the folie du pourquoi is found with delire du toucher. The patients avoid touching such and such a thing or, when they are obliged to do so, they experience a feeling of distress. There may be no reason for this repulsion, or it may be that the article in question belonged to someone they dislike, or a dead person, or even that they fear it has been soiled through contact with a person who is dirty, or infected with a contagious disease. I once nursed a girl who presented with the strange mania of never touching the back of any seat, chair, armchair or railway seat. She generally stood, or sat on the edge of the seat, so as not to come into contact with the back. The father of this girl who passed all his life for a normal, healthy man, never touched a doorknob without first covering it with a piece of his clothing, and afterwards always washed his hands".

The mania for order is just as obsessional. "Many of these unfortunate people," says Guinon, "feel an irresistible need to move objects within reach, and to replace them in an order which has been established in advance. Thus, a patient arranged everything he saw, placing half the objects on the left, half on the right." This form is analogous, though one degree more advanced, to the need for symmetry which can be observed in certain people and which I was speaking of just now.

"Hector Malot, in the novel I alluded to, in the course of the chapter I quoted, deftly exploits the known facts about this type of mania, to the extent that he invents and has described by the psychiatrist Suobyranne, the delire de l'ordre. Order pushed to extremes is, for us, a form of mental imbalance, a form of psychological neurasthenia, which I was fortunate enough to study first, and which even owes its name of boumetrie to me from (Greek) an augmentary particle and (Greek): measure. I could also have called it metrophilia, but I prefer boumetrie".

Grasset continues "Here follows a series of other forms, borrowed from Guinon: 'All the varieties of onomatomania can be observed, from the painful searching for a name and the obsession with a word which imposes itself, to fear of a compromising word which the patient is forced to omit or replace in a sentence, or else suffer great distress"."

Grasset also emphasizes arithmomania which is characteristic of GTS individuals, no matter how mild the disorder. "Finally, there is arithmomania. This is shown in some people in an overriding need to carry out arithmetical calculations. In others, it is the fear of a number whose name must not be uttered. Finally, in a certain patient, it is the need to count up to a certain number before doing something. He will count $1,2,3,4,5,7$, before getting up from his seat, for example, passing over the number 6 which he particularly dislikes. Another has to repeat 2, 3, or 10 times the same movement, turn 10 times a door handle before opening the door, or walk around 5 times in a circle before walking.

"A year ago I saw a woman who was seized at certain times by an overwhelming need to count, and could only interrupt this counting by an immense effort of will. I could give you other examples, but examples and quotations have been given in sufficient detail. I will end with Guinon's last observation which encapsulates the idea we ought to have of obsession: 'In 
research into these strange things, we should never limit ourselves to the range of fixed ideas which have already been described, for we are continually exposed to new ones. Obsession is the characteristic of this symptom, and it can show itself in a variety of ways. A patient is obliged to go up to a certain place by one staircase, and not by another, to the point where he even retraced his steps one day, having inadvertently taken the route which his singular disposition barred to him. This is a very special kind of fixed idea. But we have said that the number of fixed ideas is limitless, and that the field is open to the ingenuity and eccentricity of our patients'.

"Well: despite such a vast range of psychological stigmata, which we have examined in the minutest detail to uncover any mental disorder in our patient, that research has been fruitless. Our patient does not present with the slightest aberration of this kind" (Grasset, 1890).

Gilles de la Tourette then discusses the history of GTS, noting the contributions of Itard, Roth,Sandras, Briquet, Trousseau and Catrou, his pupil, who wrote on the disorder in 1890, using 26 case histories from Gilles de la Tourette.

Gilles de la Tourette continues: "Let us examine what constitutes this disease. It is an utterly autonomous syndrome for it is composed of elements which are always grouped together in the same form. Its development is identical in each case, which does not, however, preclude clinical variety. Despite this-and I purposely insist on this point-it presents a physiognomy which can lead to confusion with Sydenham's chorea, much to the detriment of the prognosis.

"At the age of 7 or 8, often earlier and occasionally later, a male or female child (both sexes are equally affected), whose nervous heredity is nearly always considerable, presents involuntary muscular spasms which soon attract the parents' attention, although they are not gravely alarmed in many cases. The spasms are in fact nearly always muscles which become the site of blinking, twisting movements of the mouth and brusque, rapid movements of the lips. Added to these are expiratory laryngeal sounds which may later take on a special aspect.

"The muscular spasms can be restricted to the facial muscles for some time. However, they are influenced by factors which are still hard to identify (as are those present at the onset of the first tics). The movements become generalized, extending notably to the shoulder muscles and upper limbs". He continues to describe the development of tics from shoulder shrugging, to complex movements of the whole trunk and, at a "more advanced stage, bends forward or backwards, jumping up and down, stamping his feet and bending each knee in turn".

Gilles de la Tourette then discusses the voluntary versus involuntary nature of the symptoms: "In the essay where I first described the new disease, I had classed as 'motor incoordination' all the involuntary muscular movements which can be observed in these patients. Mr Georges Guinon on the other hand, endeavoured to prove some while later that these movements were systematized and that the subjects were executing, albeit involuntarily, a coordinated movement-for example shrugging the 
shoulders, scratching the face, rubbing a part of the body, moving the hand always in the same way. This was quite important in the case of Sydenham's chorea where differential diagnosis dominates the whole issue, the involuntary movements being in this case very definitely uncoordinated. In convulsive tic disorder, however, this coordination or systematization is evident in certain cases but is very far from being absolutely constant. It will suffice to observe our patient to observe that the muscular spasms she is experiencing have nothing precise about them: expression and intensity, and in general they are limited to the face and the upper and lower left limbs. Remember their brusque, sudden nature-these more or less angular movements that Sydenham himself wrote of, concerning the disease which rightly bears his name.

"These spasms, or tics, to use the designated term, most usually begin in the facial muscles. They may extend and generalize to every part of the body, producing a massive, convulsive tic; thus, there are 'minor' and 'major' ticcers.

"The tics may be limited and infrequent in benign cases and at the onset of the disease. They may well occur at long intervals, and cease during sleep although they invariably worsen during the patient's waking hours if there is emotional stress. The patients, who are always extremely impressionable people, feel very keenly the emotions caused by pleasure or pain and external stimuli. In these circumstances the spasmodic movements will grow in intensity and at the same time their frequency and amplitude will increase, and they may become more general.

"Thus, relative calm, interrupted only by small spasms in the face and limbs, such as I described, can be replaced by attacks of muscular agitation, or paroxysms. During these attacks, the subjects will have trouble feeding themselves and carrying on with their usual business.

"The attacks vary in length. There are some which last for weeks and months at a time, broken by relatively calm periods. They have periods of increase, plateau and decline which characterize them as genuine paroxysms. But I must reiterate, to emphasize the importance of this fact, that the patients can, if asked, halt their agitation through will-power, unless it is a particularly intense attack. They can abruptly stop the movements, and this is a special characteristic of convulsive tic disorder compared, say, with Sydenham's chorea. In fact, the halt is momentary and lasts only an instant, and the movements resume all the more strongly after the act of will the subjects imposed on it. It is nevertheless a fact and its observation is, I repeat, very important as far as the diagnosis is concerned. It goes without saying that the usual mental disturbances worsen during the attacks, and this is a point to which I shall soon return.

"Once the attack is in decline, the movements become more infrequent, less intense and pronounced, and are more localized. But, some movements always remain, and this is a feature of paramount importance which I have already touched on. Spasms, particularly in the facial muscles, indicate that the disease is in fact only dormant. I have been observing several of these patients for many years, and I have in many cases been present during 
paroxysms of variable intensity. In the interval between these, I have always been able to observe twitches, limited tics which continuously bring one back to the same diagnosis".

He then goes on to discuss vocal tics such as "um" or "ah", "but, sometimes, especially when the subject is older, usually a few months or years after the onset of the muscular spasms, the previously inarticulate sound can change and take on a particular aspect, thus becoming to some extent pathognomonic.

"Here we are in the purely psychic territory of convulsive tic disorder. I have already told you that $M$. Georges Guinon had wanted to attribute coordination to the muscular twitches, postulating a willed and systematized movement which clearly had psychic implications for the symptomatic expression of the movements. I added that, as far as I am concerned, this opinion is far too comprehensive for, with the best will in the world, it is often impossible to attribute any meaning to the genuine, variable muscular incoordination which occurs in so many ticcers. This is not the case with the phenomenon I am about to describe.

"One day, under the influence of factors which are impossible to identify in most cases, the ticcer is heard to utter in a loud voice, in an abrupt fashion, a work or a brief phrase which are very special, for they have a vulgar meaning. 'Pig, bastard, shit', are the interjections which escape from the patient and for no good or even identifiable reason. These words and phrases are uttered in a loud voice without restraint and with a lack of awareness which demonstrates these subjects do indeed suffer psychic disturbances which it is important to investigate.

"Why vulgar words, you ask. Do ticcers come from those parts of society where extreme freedom in language is commonplace? Not at all. I have related in my paper the case of a young girl from the south, passed to me by Professor Pitres of Bordeaux. She came from an excellent family. This young girl was trying to pronounce the word 'Cambronne'. The unhappy parents had placed her in the charge of a governess who, whenever the child uttered a vulgar exclamation, cried out 'ah, my goodness' and so on, hoping to substitute a decent remark for the coprolalic interjection. It was hopeless. The word must be vulgar, otherwise it has no significance for the ticcer: he may well utter inarticulated 'ohs' and 'ah', but if he formulates a word its meaning will nearly always be vulgar.

"On this subject, I have been party to the confidences of a young and very distinguished Rouen woman whose son, aged 10, was a coprolalic ticcer. When she introduced him to me his embarrassed mother felt she had to assure me that my young patient could not have picked up such expressions at home. He used vulgar language quite fluently in the convulsive and spasmodic way I have mentioned.

" 'When I go out into the street with him,' she said, 'to go for a walk, I have noticed on several occasions that he listens attentively to the expressions used freely among the coachmen and doctors of whom there are many in our town. Back home, he would ask me if such and such a word that he had heard, and did not understand, could be repeated. He never failed to 
enrich his vocabulary with the vulgar ones I pointed out to him. At this point I felt the need to resort to a subterfuge, giving him the idea that certain expressions were perfectly acceptable, whereas in truth I would not dare to repeat them in front of you. I greatly regret this now. In these circumstances he would remain silent, but in spite of that he soon grew to have a vocabulary which obliges me to avoid busy places when I go out with him now, for fear of attracting the attention of passers-by.'

"It is, then, with a genuine lack of moral awareness that the coprolalic interjections are produced. At the moment they are uttered, there is an irresistible psychic impulse which drives the subject to produce vulgar words, without the least human consideration. Towards 1885, a businessman, whose case was related to me, was well known all over Bordeaux for one or two short and extremely vulgar expressions that he uttered in the street for no good reason, accompanied by convulsive twitches of the head and limbs. He was known, so his behaviour was tolerated.

"Coprolalia can, however, bring complications. A little boy from Le Havre had been placed by his mother in the care of a nurse in a house near the hospital where he went periodically for consultations. Going to the hospital, he was dawdling somewhat and stopped to watch the other children play. Absorbed in their games which he would undoubtedly like to have joined, he could not restrain himself from shouting 'pig' and 'shit' which the children took to be aimed at them. This earned him a beating.

"A bailiff's clerk from the same town, afflicted by serious tics and coprolalia, was asked by his employer to deliver injunctions to local addresses. Once he had arrived at the client's door, he rang and delivered his paper. With considerable will-power, he managed to master his tics and vulgar exclamations. When the door was closed he gave vent to these with great relief. He was, however, heard several times becoming agitated and swearing which led the clients, already quite disposed to look for another job, to one in which he could work without the same threat from coprolalia.

"Besides coprolalia, there is another psychic symptom which also occurs in ticcers, although less frequently. I have called it echolalia. It most often occurs when prompted: for example, a mother will call her daughter who is suffering from convulsive tic disorder: 'Marie, Marie!' the girl will then repeat two or three times or more the name Marie, exaggerating her tics with jumps, twitches and head movements. The phenomenon can sometimes occur spontaneously, at least in appearance, for the chosen word seems to be the exteriorization or echo of an idea which originated in the subject's brain.

"Echolalia and coprolalia are, incontestably, genuine psychic symptoms. They betray the existence of a state of mental imbalance in the ticcer. These patients, as I have said, all belong to families with a tainted psychic history and certainly seem to have a very highly charged mental state. They are subject to innumerable phobias, anxiety, transitory melancholic ideas: they are members of the group termed 'imbalanced' or, to use the expression currently in vogue, degenerates.

"I do not like that expression: it is inclined, in my view, to have too wide an application by definition. I am aware however that a superior group of 
degenerates has been postulated, one which is contrasted with those who occupy the lower rungs of the ladder of mental degeneration. Our patients ought to be classed in the upper ranks, for they sometimes litter their speech with vulgar expressions and are subject to phobias and tiresome manias but they are nevertheless mostly of above average intelligence. I have seen them occupy enviable social situations-senior officers, businessmen and lawyers are among them, and they fulfil their allotted tasks to general satisfaction. The social consequences of tic disease are an important feature of the prognosis.

"It should add that the mental signs usually appear only late on: tic disease almost always begins early; the tic starts in childhood from 6 to 10 years while coprolalia, one of the first mental signs, rarely starts before puberty or adulthood when the intellectual faculties have completely matured.

"The symptomatic ensemble of tic disease is not always complete. It may be limited to tics alone, limited or generalized and evolving in a chronic form which is likely to feature paroxysms. Even in these cases, once the subject has reached adulthood, it is rare for there not to be a certain degree of mental instability which is most likely to include echolalia and above all coprolalia which complete the morbid syndrome. The often successive appearance of these various elements is important to recognize from the point of view of the diagnosis which, as we shall see, often presents difficulties if certain morbid features are absent. Whether the picture is complete or not, the prognosis is nevertheless the same. Once they begin, the tics never disappear. They are altered in appearance and evolve in the form of paroxysms variable in length and intensity. However, in the intervals between them-I must insist on this fundamental point - there persist more or less attenuated tics which enable an experienced observer to recognize the disease.

"There can be no hope of a cure; the paroxysms can be calmed by an appropriate treatment and the tics can be reduced in intensity so that the subject suffers as little as possible. But there can be no question of the complete elimination of this morbid state which has become, as it were, a function of the individual since it is a product of his constitutional mental state.

"I have confined myself to the symptomatology and evolution of convulsive tic disorder because this seemed indispensable in the interest of the diagnosis, which often needs clarification. Perhaps these precautions seem unnecessary to you, given the very distinct physiognomy of the disease. Think again-although it is 15 years since I isolated this morbid syndrome, the reality is nonetheless that the disease is still, only too often, wrongly diagnosed, with consequences that should be avoided from the purely practical point of view, as you will see, quite apart from any doctrinal considerations.

"I shall remind you once again-and this is most important-the convulsions" and tics are always the first symptoms to appear. They begin during childhood between age 6 and 8 . For a long while they may be the 
only symptoms. Echolalia and coprolalia and the various mental signs appear only later in most cases. It is undoubtedly during this period that the disease is most likely to be confused with other morbid conditions which differ in type and evolution, and among these there is one which is more likely than any other to cause confusion: you can guess that I am talking about Sydenham's chorea".

[Gilles de la Tourette discusses at length how often he sees patients with GTS and states again that the patients have previously had incorrect diagnoses and therefore incorrect prognoses and treatment. He asserts that a faulty prognosis "is not forgiven in practice" and emphasizes the dangers of treating a patient incorrectly with arsenic.]

Gilles de la Tourette then compares and contrasts the movements of GTS and Sydenham's chorea: "Sydenham's chorea and convulsive tic disorder do, however, differ fundamentally ... Ticcers' movements are brief, jerky, convulsive and sometimes systematized; in chorea they are more developed, rounded and contoured, as Sydenham said, expressing the essence of this disease so well in just a few lines: incoordination is the rule. Finally, as the great English clinician observed quite precisely, the will is powerless to stop choreic movements-if the subject concentrates on them he is more likely to aggravate them, whereas the ticcer can, by a psychic effort, momentarily halt his convulsive movements. I shall not even mention echolalia and coprolalia which would remove all doubt if indeed any remains; I shall confine myself for now to the comparison between choreic movements and the spasm of a convulsive tic ... Perhaps you think we might isolate a further element of differential diagnosis in the fact that Sydenham's chorea is often accompanied by so-called rheumatic features in the form of transitory arthropathy. I do not recommend that you pursue this notion-you would be most disappointed ... Personally, I am of this opinion: it has to be said that in contrast with most writers who have studied chorea since Germain See (1850), tic disease has nothing to do with rheumatism. Although I have looked for them, I have not once observed these arthropathic symptoms in the numerous cases of Sydenham's chorea that special study has enabled me to study ... Choreic patients are forced to take to their beds; fever can develop and a child exhausted by such disorderly agitation can often succumb under the influence of the slightest visceral complication, or perhaps through the muscular agitation alone ... In these cases it is unusual not to see these paralytic phenomena which have lent their name to paralytic or 'limp' chorea as the English call it ... Nothing comparable occurs in the case of convulsive tic disorder whose gravest paroxysms always have a favourable prognosis. You can judge the importance of correct diagnosis in these particular instances ... Till now, I have only considered diagnosing the difference between chorea and convulsive tic disorder in children. 'There is no chorea after puberty', said Sydenham, who cannot be quoted too often".

[Gilles de la Tourette then discusses another differential diagnosisHuntington's disease (or chronic chorea), with a later age of onset, typical 
muscular movements, characteristic mental state, positive family history and no echolalia nor coprolalia.]

"There is one more kind of choreic movements which could affect the diagnosis. I mean those of hysterical chorea. This disorder is exceptional at the age in which convulsive tics generally appear. It rarely strikes before puberty and occurs almost exclusively in women. What is more, the movements almost always have a special character-they are rhythmicthis is the malleatory, saltatory chorea which you have learned to recognize. Also, it is unusual for patients' signs of hysteria to be confined to choreic movements: most of the time there are permanent symptoms which will prove invaluable to you, and often the choreic paroxysms result in attacks of true convulsions which would clarify the issue, should any doubt remain.

"There are, nevertheless, certain cases which are quite difficult to assess-firstly, hysterical chorea can be arrhythmic; Mr Dettling has described many telling features of this kind in his inaugural paper. This is fullblown Sydenham's chorea which has been brought on by that great pretender: hysteria. The subject's age and the presence of mental symptoms will help you greatly here. Sydenham's chorea rather than tic disease is likely to be diagnosed and you know that, after the age of 15 or 16 , there is no true chorea.

"It can still happen that hysteria itself may produce tics which confusingly resemble those I have described to you: the onset of these at an advanced age, the existence of other hysterical signs and the evolution of the tics will enable you to judge the nature of these. Finally, M. G. Guinon has published a few cases of hysterical behaviour in confirmed ticcers - this is a morbid conjunction that you should consider too; the tics will nearly always be the first features to appear in the evolution of the symptoms".

[Gilles de la Tourette again reiterates that the most common mistakes in diagnosis will be between GTS and Sydenham's chorea. He then briefly mentions chorea gravidarum - which "has nothing to do with Sydenham's chorea and is a feature of hysteria", "electric chorea or Dubini's disease which is probably infectious and has no connection with chorea", Bergeron's chorea, Morvan's fibrillary chorea and Friedreich's multiplex paramyoclonus, "all conditions which have no clearly-defined place in the medical framework".]

"Finally, I come to a disorder which M. Brissaud described in 1897 under the definition of variable, degenerates' chorea, and which his pupil, M. Patry, discussed in his thesis. In my opinion, I must say straight away, this disease cannot be distinguished from convulsive tic disorder and I have borrowed the elements of my argument from the last published work of M. Brissaud on the subject, from February 1899.

"It concerns a young girl of 16 . This is what M. Brissaud says about her movements.

" 'The patient had been admitted to hospital for chorea and in fact the first time she was examined, the symptoms of common chorea were so typical that this was diagnosed without hesitation. But the following day, 
the chorea had already altered - there were brusque, forward movements of the arms, shrugs of the shoulders and the electric, sudden and violent spasms which bore no relation to the "round" and relatively supple movements of Sydenham's chorea'.

"Through exercising her will-power, the patient could make the movements cease, at least momentarily. Her mental state was degenerate and, finally, there was coprolalia. Jerky and variable movements; possibility of halting the movement of will; coprolalia; the mental state: these are precisely the characteristics I attributed to convulsive tic disorder in my first publication. I do not see how variable degenerative chorea can be distinguished from it. The variable symptoms that $\mathbf{M}$. Brissaud attributes to the disease he describes occur very markedly in tic disease and the common confusion with Sydenham's chorea shows, as we have said, that the argument that tics are always systematic (which I have always refused to countenance), is exaggerated, to say the least.

"What I have told you here of convulsive tic disorder has already given you some idea of its prognosis. There are both small and large tics-the former pass almost unnoticed and in no way hinder physical functions and social relations. The latter, which are true paroxysms, cause great inconvenience and sometimes oblige the subject to stay in during attacks and to stop work. The serious features are the complexity or the simplicity of the various symptoms, the frequency of attacks and the possibility of repetition, even after long periods of calm. But a common link unites all cases, and that is their permanence, so to speak. Once a ticcer, always a ticcer. In the interval between serious paroxysms, when they occur, muscular spasms can still be observed-in a word, tics are either pronounced or not and these never disappear, as can be confirmed if the patient is carefully examined and closely supervised over a long period. Once they have appeared, I repeat, the tics are as it were a function of the individual and, as they have as a psychic substratum a mental state which invariably causes some discomfort, it follows that, all things considered, tic disease carries a relatively severe prognosis: the outward signs must be alleviated if possible, at least as long as they have a paroxystic appearance.

"This is the direction treatment should take. Fatigue of all kinds, primarily moral, should be scrupulously avoided in these patients - a period of calm, in the country, even in isolation will be the best aids to a cure which can radically alter the morbid state which has been brought on. However it will only be truly successful in alleviating the outward symptoms, above all in their paroxystic form."

These papers are not only monuments to clinical description, but also some of the first to consider that psychopathology, with special reference to obsessive-compulsive behaviours and OCD, which is now recognized as an integral part of GTS.

What is known about the clinical picture and psychopathology of GTS today? It is now known that the clinical characteristics of patient with GTS appear to be independent of culture, as they occur with some degree of uniformity irrespective of the country of origin. The age of onset of GTS 
symptoms ranges from 2 to 15 years with a mean of 7 years being commonly reported. The most frequent initial symptoms are tics involving the eyes, head nodding and facial grimacing which are also the most common tics. GTS is often referred to as a tic disorder, but patients with GTS usually exhibit a wide variety of complicated movements including touching, hitting, jumping, smelling of the hands or objects, spitting, kicking, stamping, squatting and a variety of complexities of gait (Robertson, 1989). The onset of vocalizations is usually later than that of the motor tics, with a mean age of 11 years, and grunting, sniffing, coughing, throat-clearing, barking, snorting, explosive utterances, screaming, humming, hissing, clicking, colloquial emotional exclamations and inarticulate sounds are the usual utterances. Coprolalia (the involuntary inappropriate uttering of obscenities) is reported in approximately one-third of patients and usually has a mean age of onset of 14 years. Copropraxia (the involuntary and inappropriate making of obscene gestures) is reported in 3\%-21\% of GTS patients. Echolalia (the imitation of sounds or words) and echopraxia (imitation of actions) occur in $11 \%-44 \%$ of patients. Tics and vocalizations are characteristically aggravated by anxiety, stress, boredom, fatigue and excitement, while sleep, alcohol, orgasm, fever, relaxation or concentration lead to temporary disappearance of symptoms (Robertson, 1989).

Many types of associated behaviours have been reported in patients with GTS. Wilson et al. (1982) reported that children with GTS had significantly more behaviour problems than those in a control group. No specific abnormalities or patterns of difficulties were found, and the severity of the behaviour problems correlated directly with the severity of the movement disorder and inversely with the IQ.

Some types of behaviour, such as OCD are intimately linked to GTS (see below) and are thus probably an integral part of the syndrome, whereas others such as hyperactivity, attention deficit disorder and learning difficulties occur in a substantial number of patients $(30 \%-60 \%)$ and, as they are probably often the symptoms for which the patient is referred to the physician (Robertson, 1989), they are overrepresented in clinical populations. Antisocial behaviour, inappropriate sexual activity, exhibitionism, aggressive behaviour and discipline problems and self-injury are found in a substantial percentage of clinic GTS populations (Robertson, 1989; Robertson et al., 1989). From our experience in clinical (Robertson et al., 1988; Robertson et al., 1989) and pedigree (Robertson and Gourdie, 1990) settings, and from the data of epidemiological surveys (Caine et al., 1988), it is suggested that relatively few GTS subjects in the community exhibit antisocial behaviours and that they are mild and not requiring treatment (Robertson, 1989).

It seems that GTS and OCD have always had an intertwined history. Itard (1825) and Gilles de la Tourette (1885) both described GTS symptoms in the Marquise de Dampierre and it is of interest that she may have also manifested symptoms of OCD in addition to her tic disorder. A convincing case has been made that the 18th century literary figure Dr Samuel Johnson suffered from GTS (McHenry, 1967; Murray, 1979). Miss Lucy Porter told 
James Boswell (1867) that when Dr Johnson "was introduced to her mother, his appearance was very forbidding; ... he often had, seemingly, convulsive starts and odd gesticulations, which tended at once surprise and ridicule". $\mathrm{He}$ apparently had a wide repertoire of motor tics such as mouth opening, lip pursing, eye squinting, and perpetual convulsive movements of the hands and feet. He had vocalizations including "ejaculations of the Lord's prayer", whistling sounds, sounds like the clucking of a hen and of a whale exhaling (Boswell, 1867; McHenry, 1967; Murray, 1979). He also exhibited echolalia and mild self-injurious behaviour, and it has also been suggested that Dr Johnson suffered from severe OCD in addition to his motor and vocal tics. Thus he felt impelled to measure his footsteps, perform complex gestures when he crossed a threshold and involuntarily touch specific objects (Murray, 1979).

In the 1889 paper of Gilles de la Tourette which we have presented, he noted the ideas of Guinon (1886) who suggested that "ticcers" nearly always had associated psychiatric disorders characterized by multiple phobias, arithmomania and agoraphobia. Grasset (1890) also referred to the obsessions and phobias of patients, which were to him an accompaniment of the tic disorder, representing psychical tics.

Thereafter Pierre Janet in 1903, in his treatise "Les Obsessions et la Psychasthenie", described three stages of psychasthenic illness: the first was the "psychasthenic state", the second "forced agitations", which included motor tics, while the third was obsessions and compulsions (Pitman, 1987).

Meige and Feindel (1907), in "confessions of a victim to tic", described a patient whom they consider to be the prototype of a tic patient. In retrospect, it is clear that this patient would now be diagnosed as having GTS. He had motor tics which began at the age of 11 years, echophenomena (copying behaviours), a "tic of phonation dating back to his fifteenth year" and "an impulse to use slang". In addition he was impulsive, had suicidal tendencies and had obsessive-compulsive behaviour. Meige and Feindel (1907) state: "the frequency with which obsessions, or at least a proclivity for them, and tics are associated, cannot be a simple coincidence". They describe case histories of patients with typical features of OCD including the relief of anxiety that accompanied the carrying out of a particular motor act. However, in addition to the close link between the motor movement and a compulsion, they noted that often there was no direct connection between a patient's obsessions and the tics, the former occurring in the form of extraordinary scrupulousness, phobias and excessive punctiliousness in their actions. They specifically mentioned arithmomania, onomatomania (the dread of uttering a forbidden word or the impulse to intercollate another) and folie du pourquoi, which is the irresistible habit of seeking explanations for the most commonplace facts by asking perpetual questions. KinnearWilson, the neurologist, also acknowledged a relationship between tics and OCD: "no feature is more prominent in tics than its irresistibility ... The element of compulsion links the condition intimately to the vast group of obsessions and fixed ideas". Ascher (1948) noted that all of the five GTS 
patients he reported had obsessive personalities, while Bockner (1959) commented that the majority of GTS cases described in the literature had obsessive-compulsive neurosis.

There is a growing literature in modern scientific writings on the relationship between OCD and GTS, and it is becoming increasingly evident that there is a clear and strong association between the two disorders (Robertson, 1989). To date 11 studies have documented GTS patients as having obsessional symptoms, traits or illness, in significant percentages of patient populations: 11\% (Kelman, 1965), 31\% (Fernando, 1967), 32\% (Comings and Comings, 1985), 33\% (Abuzzahab and Anderson, 1973), $38 \%$ (Asam, 1982), and as high as 60\% (Hagin et al., 1982), 66\% (Montgomery et al., 1982), 68\% (Nee et al., 1980), 71\% (Morphew and Sim, 1969), 74\% (Stefl, 1984) and 80\% (Yaryura-Tobias et al., 1981). Moreover, in controlled studies (Frankel et al., 1986; Green and Pitman, 1986; Comings and Comings, 1987; Van de Wetering et al., 1988) GTS patients were found to have higher scores on obsessive-compulsive inventories and to show more obsessive-compulsive behaviours than normal controls. The scores and behaviour ratings were as high as those of patients with OCD. Robertson $e t$ al. (1988) found that $37 \%$ of clinic GTS patients have obsessive compulsive behaviours and, using standardized rating scales, found much higher scores in GTS patients compared with normative data. In addition, coprolalia and echophenomena were significantly associated with obsessive-compulsive phenomena (Robertson et al., 1988). The argument for a strong association between GTS and OCD also comes from both pedigree (Kurlan et al., 1986, 1987; Pauls et al., 1986a, b; Comings and Comings, 1987; Robertson and Gourdie, 1990; Robertson and Trimble, 1990) and epidemiological (Caine $e t$ al., 1988) studies which suggest that not only do patients with mild GTS have significant obsessive-compulsive behaviours, but also that OCD may well be a phenotype of the anticipated GTS gene(s). It is therefore of added interest that in the GTS twin study of Jenkins and Ashby (1983), both twins were described as obsessional.

One may also examine the association between GTS and OCD from the perspective of OCD patients, and Rapoport (1988) noted that about $20 \%$ of OCD patients have tics. It is also important therefore to note that functional abnormalities in the basal ganglia have been shown both in GTS and OCD. Thus in GTS patients abnormalities in the basal ganglia and frontal cingulate and possibly insular cortex have been reported (Chase et al., 1984, 1986), while non-specific frontal abnormalities (Behar et al., 1984, Garber $e t$ al., 1989) and basal ganglia dysfunction, especially in the caudate nucleus, and orbito-frontal cortex have been suggested as of aetiological importance in OCD (Laplane et al., 1981, 1982; Baxter et al., 1987; Luxenberg et al., 1988; Williams et al., 1988; Swedo et al., 1989). Further evidence for the link comes from the fact that there are studies indicating that genetic factors may be important in both the aetiology of OCD (Luxenburger, 1930; Lewis, 1935; Brown, 1942; Kringlen, 1965; Rosenberg, 1967; Carey, 1978; Insel et al., 1983; Rasmussen and Tsuang, 1986; Lenane et al., 1988; Pauls et al., 1988) and GTS (Kurlan et al., 1986, 1987; Robertson 
and Gourdie, 1990; Robertson and Trimble, 1990). However, further work in the area is needed to know the exact genetic mechanisms involved in GTS and $O C D$, and whether OCD is related genetically and phenomenologically to GTS.

Apart from the relationship between GTS and OCD, the general psychopathology of GTS has also received some attention in the literature. Patrick (1905), in his writings on "convulsive tic", described GTS as "the disease of tics - the entire body is affected by peculiar, sudden, more or less violent, intempestive, malapropos gestures", but then acknowledged the psychiatric aspects thus: "The expression convulsive tic implies a motor malady. This is only half the truth, and, if one may be pardoned a hibernianism, the lesser half". He then goes on to suggest that GTS is a "sensori-psychomotor derangement".

Psychoanalytical speculation then dominated the literature, with notably Ferenczi (1921), who suggested that tics may turn out to be stereotyped equivalents of "onanism" and tics were closely related to narcissism. He likened the origin of the tics to that of hysterical conversion symptoms, hinting at past trauma and retrogression of incompletely abreacted effects. The ideas of Ferenczi were perpetuated by Mahler and colleagues (Mahler and Rangell, 1943; Mahler, 1944; Mahler et al., 1945; Mahler and Luke, 1946), who, while acknowledging that the symptoms of GTS were probably mediated via striopallidal connections, suggested they occurred in highly narcissistic individuals with disturbed psychosexual development and parent-child relationships. Thereafter Fenichel (1945) suggested that tics were involuntary motor equivalents of emotional activity, allowing hitherto repressed impulses to be expressed in disguised forms. Subsequently, the relationship of GTS to psychosis was addressed by the analysts, who distinguished single tics (one of a series of neurotic symptoms) from generalized tics, which were seen as a defence against becoming psychotic (Heuscher, 1953).

The psychopathology of GTS subsequent to 1965 is somewhat controversial. Thus the Shapiro groups (Shapiro et al., 1978; Shapiro and Shapiro 1982) fail to observe an association between GTS and any specific psychiatric syndrome or psychodynamic factors, suggesting that GTS patients do not differ significantly from general psychiatric out-patients with respect to obsessive-compulsive traits, inhibition of hostility, hostility, hysteria and general maladjustment and that the majority of GTS patients have various types of "personality disorders". They agree however that there may be a subgroup of GTS patients who have a great deal of difficulty with compulsive ritualistic behaviour. Grossman et al. (1986) reported that GTS patients score higher than matched controls on the following subscales of the MMPI: schizophrenia, depression, psychopathic deviate, psychasthenia and hypochondriasis.

Corbett et al. (1969) compared the psychopathology of ticcers (including patients with GTS) with that of disturbed children, and found that ticcers had significantly more habit disorders, obsessional symptoms and hypochondriasis, and significantly fewer conduct disorders. Morphew and Sim (1969) 
described a high incidence of childhood neurotic traits in GTS patients, as well as a high proportion (33\%) of enuretics; this was regarded as particularly noteworthy, as just under half of these were female, which is higher than would be expected as the condition is more common in boys. Phobic features were also common. There were 21 recorded personality problems, with hysterical psychopathics, paranoid and hysterical being common. Morphew and Sim felt that the psychopathology was associated with hostility and aggression, directed particularly at a parent or spouse. Montgomery et al. (1982) described secondary affective disorder in association with GTS while Van de Wetering (personal communication) found that children with GTS were significantly more anxious and depressed than a matched control population. Comings and Comings (1987) reported significantly more depression in GTS patients than in controls, as well as a high "mania" score. Robertson et al. (1988) reported that over half of GTS patients were depressed and that the depression score was related to the duration of the illness.

It seems therefore that patients with GTS are especially prone to depression, which is probably related to the duration of the GTS: this could be explained, at least in part, by the fact that GTS sufferers have a chronic, socially disabling and stigmatizing disease. A genetic predisposition to depressive illness should also, however, be borne in mind. Finally there is no association between psychosis and GTS apart from a few case reports (Bleich et al., 1985; Burd and Kerbeshian, 1984; Caine et al., 1978; Takeuchi et al., 1986).

In conclusion it seems that psychopathology, with particular reference to OCD, is an important part of GTS and this was recognized by early clinicians such as Gilles de la Tourette, Guinon and Grasset whose impressive clinical descriptions we have presented in English for the first time. Brain-imaging, neurochemistry and genetics are current areas of research in both GTS and OCD and will lead to further understanding of the relationships between the two disorders.

\section{References}

American Psychiatric Association (1987). Diagnostic and Statistical Manual of Mental Disorders (3rd edn, revised) (DSM-111-R). American Psychiatric Association, Washington DC.

Abuzzahab, F. E. and Anderson, F. O. (1973). Gilles de la Tourette's syndrome. Minnesota Medicine, 56, 492-496.

Asam, U. (1982). A follow-up study of Tourette syndrome. In "Gilles de la Tourette Syndrome" (Eds A. J. Friedhoff and T. N. Chase), Advances in Neurology, Vol. 35, Raven Press, New York.

Ascher, E. (1948). Psychodynamic considerations in Gilles de la Tourette's disease (maladie des tics): with a report of five cases and discussion of the literature. American fournal of Psychiatry, 105, 267-276.

Baxter, L. R., Phelps, M. E., Mazziotta, J. C. et al. (1987). Local cerebral glucose metabolic rates in obsessive-compulsive disorder. A comparison with rates in unipolar depression and in normal controls. Archives of General Psychiatry, 44, 211-218. 
Behar, D., Rapoport, J. L., Berg, M. A. et al. (1984). Computerised tomography and neuropsychological test measures in adolescents with obsessive-compulsive disorder. American Fournal of Psychiatry, 141, 363-369.

Bleich, A., Bernout, E., Apter, A. et al. (1985). Gilles de la Tourette syndrome and mania in an adolescent. British Fournal of Psychiatry, 146, 664-665.

Bockner, S. (1959). Gilles de la Tourette's disease. Journal of Mental Science, 105, 1078-1081.

Boswell, J. (1867). "The Life of Samuel Johnson LLD". George Routledge \& Sons, London.

Brown, F. W. (1942). Heredity in the psychoneuroses (summary). Proceedings of the Royal Society of Medicine, 35, 785-790.

Burd, L. and Kerbeshian, J. (1984). Gilles de la Tourette's syndrome and bipolar disorder. Archives of Neurology, 41, 1236.

Caine, E. D., Margolin, D. I., Brown, G. L. et al. (1978). Gilles de la Tourette's syndrome, tardive dyskinesia and psychosis in an adolescent. American fournal of Psychiatry, 135, 241-243.

Caine, E. D., McBride, M. C., Chiverton, P. et al. (1988). Tourette syndrome in Monroe county school children. Neurology, 38, 472-475.

Carey, G. (1978). A Clinical Genetic Twin Study of Obsessive and Phobic States. PhD Thesis, University of Minnesota.

Chase, T. N., Foster, N. L., Fedio, P. et al. (1984). Gilles de la Tourette syndrome: studies with the fluorine-18-labelled fluorodeoxyglucose positron emission tomographic method. Annals of Neurology, 15 (Suppl.), S175.

Chase, T. N., Geoffrey, V., Gillespie, M. et al. (1986). Structural and functional studies of Gilles de la Tourette syndrome. Revue Neurologique (Paris), 142, 851-855.

Comings, D. E. and Comings, B. G. (1985). Tourette syndrome: Clinical and psychological aspects of 250 cases. American Fournal of Human Genetics, 37, 435-450.

Comings, D. E. and Comings, B. G. (1987). A controlled study of Tourette syndrome, I-VII. American Journal of Human Genetics, 41, 701-866.

Corbett, J. A., Matthews, A. M., Connell, P. H. et al. (1969). Tics and Gilles de la Tourette's syndrome: a follow-up study and critical review. British fournal of Psychiatry, 115, 1229-1241.

Fenichel, O. (1945). "The Psychoanalytic Theory of Neurosis". Norton and Company, New York.

Ferenczi, S. (1921). Psycho-analytical observations on tic. International Journal of Psychoanalysis, 2, 1-30.

Fernando, S. J. M. (1967). Gilles de la Tourette's syndrome: a report on four cases and a review of published case reports. British Fournal of Psychiatry, 113, 607-617.

Frankel, M., Cummings, J. L., Robertson, M. M. et al. (1986). Obsessions and compulsions in Gilles de la Tourette's syndrome. Neurology, 36, 378-382.

Garber, H. J., Ananth, J. V., Chiu, L. C. et al. (1989). Nuclear magnetic resonance study of obsessive-compulsive disorder. American Fournal of Psychiatry, 146, 1001-1005.

Gilles de la Tourette, G. (1885). Etude sur une affection nerveuse caracterisée par de l'incoordination motrice accompagné d'echolalie et de copralalie. Archives of Neurology, 9 , $19-42,158-200$.

Gilles de la Tourette, G. (1889). La maladie des tics convulsifs. La Semaine Medicale, 19, $153-156$.

Grasset, J. (1890). Leçons sur un cas de maladie des tics et un cas de tremblement singulier de la tête et des membres gauches. Archives of Neurology, 20, 27-45, 187-211.

Green, R. G. and Pitman, R. K. (1986). Tourette syndrome and obsessive-compulsive disorder. In "Obsessive-Compulsive Disorders: Theory and Management" (Eds M. A. Kenike, L. Baer and W. O. Minichiello). PSGP Publishing Co, Littleton MA.

Grossman, H. Y., Mostofsky, D. I. and Harrison, R. H. (1986). Psychological aspects of Gilles de la Tourette syndrome. Fournal of Clinical Psychology, 42, 228-235.

Guinon, G. (1886). Sur la maladie des tics convulsifs. Revue de Medicin, 6, 50-80.

Hagin, R. A., Beecher, R., Pagano, G. et al. (1982). Effects of Tourette syndrome on learning. In "Gilles de la Tourette Syndrome" (Eds A. J. Friedhoff and T. N. Chase). Advances in Neurology, Vol. 35, Raven Press, New York. 
Heuscher, J. E. (1953). Intermediate states of consciousness in patients with generalised tics. Fournal of Nervous and Mental Disease, 117, 29-38.

Insel, T. R., Hoover, C. and Murphy, D. L. (1983). Parents of patients with obsessivecompulsive disorder. Psychological Medicine, 13, 807-811.

Itard, J. M. G. (1825). Mémoire sur quelques fonctions involuntaires des appareils de la locomotion de la prehension et de la voix. Archives of General Medicine, 8, 385-407.

Jenkins, R. L. and Ashby, H. B. (1983). Gilles de la Tourette syndrome in identical twins. Archives of Neurology, 40, 249-251.

Kelman, D. H. (1965). Gilles de la Tourette's disease in children: a review of the literature. Journal of Child Psychology and Psychiatry, 6, 219-226.

Kringlen, E. (1965). Obsessional neurotics: a long term follow-up. British Fournal of Psychiatry, 111, 709-722.

Kurlan, R., Behr, J., Medved, L. et al. (1986). Familial Tourette's syndrome: report of a large pedigree and potential for linkage analysis. Neurology, 36, 772-776.

Kurlan, R., Behr, J., Medved, L. et al. (1987). Severity of Tourette's syndrome in one large kindred: implication for determination of disease prevalence rate. Neurology, 44, 268-269.

Laplane, D., Widlocher, D., Pillon, B. et al. (1981). Compulsive behaviour of the obsessional type with bilateral circumscribed pallidostriatal necrosis (encephalopathy following a wasp sting). Revue Neurologique (Paris), 137, 269-276.

Laplane, D., Baulac, M., Pillon, B et al. (1982). Perte de l'auto-activation psychique. Activité compulsive d'allure obsessionelle. Lesion lenticulare bilaterale. Revue Neurologique (Paris), 138, 137-141.

Lenane, M. C., Swedo, S. E., Leonard, H., Cheslow, D. L., Rapoport, J. L. and Pauls, D. L. (1988). Obsessive compulsive disorder in first degree relatives of obsessive compulsive disorder children. Proceedings of the APA, Montreal, Canada.

Lewis, A. (1935). Problems of obsessional illness. Proceedings of the Royal Society of Medicine, 29, 325-336.

Luxenberg, J. S., Swedo, S. E., Flament, M. F. et al. (1988). Neuroanatomical abnormalities in obsessive-compulsive disorder. American Fournal of Psychiatry, 145, 1089-1093.

Luxenberger, H., (1930). Hereditat und Familientypus der Zwangsneurotiker. Archiv für Psychiatrie, 91, 590-594.

Mahler, M. S. (1944). Tics and impulsions in children: a study of motility. Psychoanalytic Quarterly, 13, 430-444.

Mahler, M. S. and Luke, J. A. (1946). Outcome of the tic syndrome. Fournal of Nervous and Mental Disease, 103, 433-445.

Mahler, M. S. and Rangell, L. (1943). A psychosomatic study of maladie des tics (Gilles de la Tourette's Disease). Psychiatric Quarterly, 17, 579-603.

Mahler, M. S., Luke, J. A. and Daltroff, W. (1945). Clinical and follow up study of the tic syndrome in children. American Fournal of Orthopsychiatry, 15, 631-647.

McHenry, L. C. Jr (1967). Samuel Johnson's tics and gesticulations. Fournal of the History of Medicine, 22, 152-168.

Meige, H. and Feindel, E. (1907). "Tics and Their Treatment". (Transl. and Ed. S. A. K. Wilson). William Wood and Company, New York.

Montgomery, M. A., Clayton, P. J. and Friedhoff, A. J. (1982). Psychiatric illness in Tourette syndrome patients and first-degree relatives. In "Gilles de la Tourette Syndrome" (Eds A. J. Friedhoff and T. N. Chase). Advances in Neurology, Vol. 35, Raven Press, New York.

Morphew, J. A. and Sim, M. (1969). Gilles de la Tourette's syndrome: a clinical and psychopathological study. British Journal of Medical Psychology, 42, 293-301.

Murray, T. J. (1979). Dr Samuel Johnson's movement disorders. British Medical Journal, i, 1610-1614.

Nee, L. E., Caine, E. D., Polinsky, R. J. et al. (1980). Gilles de la Tourette syndrome: clinical and family study of 50 cases, Annals of Neurology, 7, 41-49.

Patrick, H. T. (1905). Convulsive tic. Fournal of the American Medical Association, 44, 437-442.

Pauls, D. L., Leckman, J., Towbin, K. E. et al. (1986a). A possible genetic relationship exists 
between Tourette's syndrome and obsessive-compulsive disorder. Psychopharmacology Bulletin, 22, 730-733.

Pauls, D. L., Towbin, K. E., Leckman, J. F. et al. (1986b). Gilles de la Tourette's syndrome and obsessive compulsive disorder. Archives of General Psychiatry, 43, 1180-1182.

Pauls, D. L., Raymond, C. L., Hurst, C. R., Rasmussen, S., Goodman, W. and Leckman, J. F. (1988). Transmission of obsessive compulsive disorder and associated behaviours. Proceedings of the 43rd Meeting of the Society of Biological Psychiatry, Montreal, Canada.

Pitman, R. K. (1987). Pierre Janet on obsessive compulsive disorder (1903). Archives of General Psychiatry, 44, 226-232.

Rapoport, J. L. (1988). The neurology of obsessive-compulsive disorder. Fournal of the American Medical Association, 260, 2888-2890.

Rasmussen, S. A. and Tsuang, M. T. (1986). Clinical characteristics and family history in DSM111 obsessive-compulsive disorder, American Fournal of Psychiatry, 143, 317-322.

Robertson, M. M., Trimble, M. R., Lees, A. J. (1988). The psychopathology of the Gilles de la Tourette syndrome: a phenomenological analysis, British Journal of Psychiatry, 152, 383-390.

Robertson, M. M. (1989). The Gilles de la Tourette Syndrome: The current status. British Fournal of Psychiatry, 154, 147-169.

Robertson, M. M., Trimble, M. R. and Lees, A. J. (1989). Self-injurious behaviour and the Gilles de la Tourette syndrome. A clinical study and review of the literature. Psychological Medicine, 19, 611-625.

Robertson, M. M. and Gourdie, A. (1990). Familial Tourette's syndrome in a large British pedigree: Associated Psychopathology, Severity of Tourette's and Potential for Linkage Analysis. British Fournal of Psychiatry, 156, 515-521.

Robertson, M. M. and Trimble, M. R. (1991). Gilles de la Tourette syndrome in the Middle East: report of a cohort and a multiply affected large pedigree. British Journal of Psychiatry, 158, 416-419.

Rosenberg, C. M. (1967). Familial aspects of obsessional neurosis. British Fournal of Psychiatry, 113, 405-413.

Shapiro, A. K., Shapiro, E. S., Bruun, R. D. and Sweet, R. D. (1978). "Gilles de la Tourette Syndrome". New York, Raven Press.

Shapiro, A. K. and Shapiro, E. S. (1982). Tourette syndrome; history and present status. In: "The Gilles de la Tourette Syndrome", Advances in Neurology, Vol. 35 (Eds A. J. Friedhoff and T. N. Chase) pp. 17-23. Raven Press, New York.

Stefl, M. E. (1984). Mental health needs associated with Tourette syndrome. American fournal of Public Health, 74, 1310-1313.

Swedo, S. E., Rapoport, J. L. and Cheslow, D. L. (1989). High prevalence of obsessivecompulsive symptoms in patients with Sydenham's chorea. American Fournal of Psychiatry, 146, 246-249.

Takeuchi, K., Yamashita, M., Morikiyo, M. et al. (1986). Gilles de la Tourette's syndrome and schizophrenia. Fournal of Nervous and Mental Disease, 174-248.

Van de Wetering, B. J. M., Cohen, A. P., Minderaa, R. B. et al. (1988). Het Syndroom van Gilles de la Tourette: Klinische Bevindigen. Nederlande Tijdschriff Geneeskunde, 132, 21-25.

Williams, A. C., Owen, C. and Heath, D. A. (1988). A compulsive movement disorder with cavitation of caudate nucleus, Journal of Neurology, Neurosurgery and Psychiatry, 51, $447-448$.

Wilson, R. S., Garron, D. C., Tanner, C. M. et al. (1982). Behavior disturbance in children with Tourette Syndrome. In "The Gilles de la Tourette Syndrome" (Eds A. J. Friedhoff and T. N. Chase), Advances in Neurology, Vol. 35. Raven Press, New York.

Wilson, S. A. K. (1927). Tics and child conditions. Fournal of Neurology and Psychopathology, 8, 93-109.

Yaryura-Tobias, J. A., Neziroglu, F., Howard, S. et al. (1981). Clinical aspects of Gilles de la Tourette syndrome. Fournal of Orthomolecular Psychiatry, 10, 263-268. 


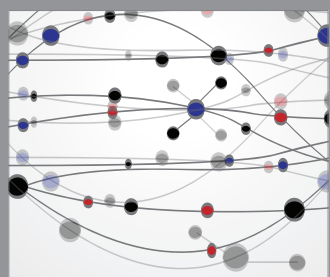

The Scientific World Journal
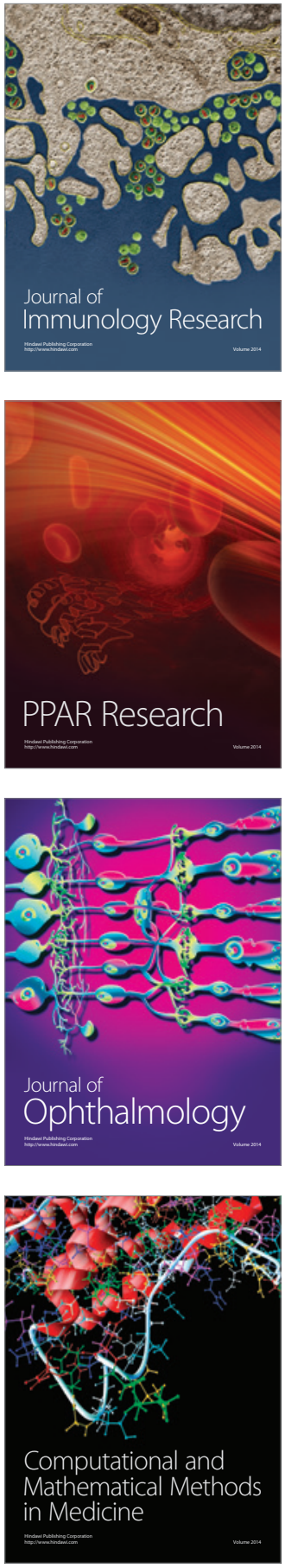

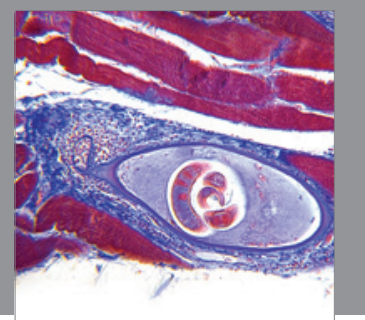

Gastroenterology

Research and Practice
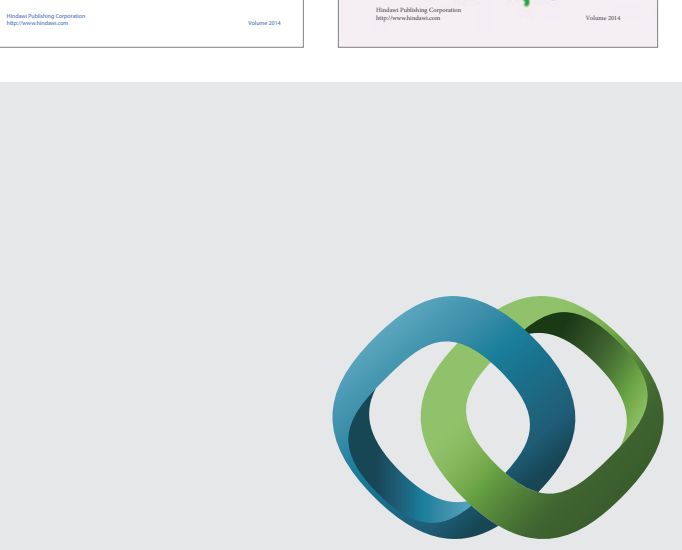

\section{Hindawi}

Submit your manuscripts at

http://www.hindawi.com
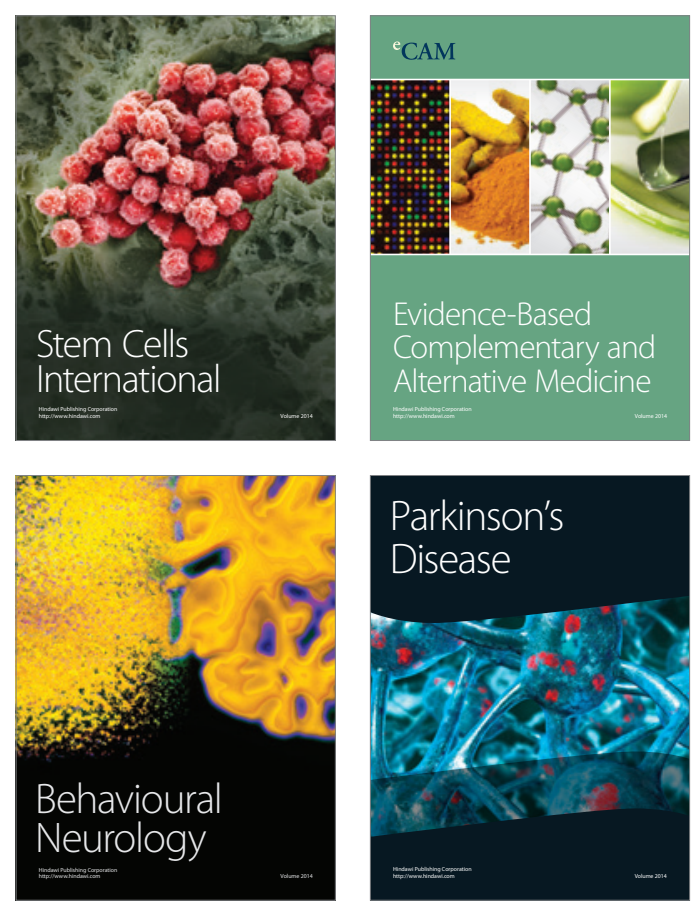

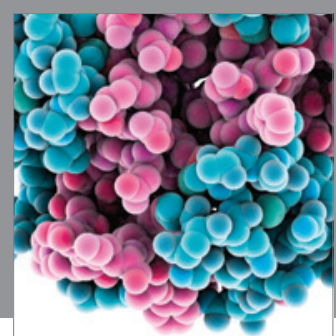

Journal of
Diabetes Research

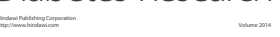

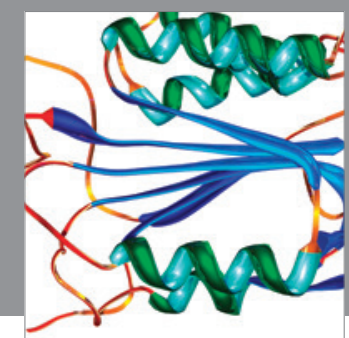

Disease Markers
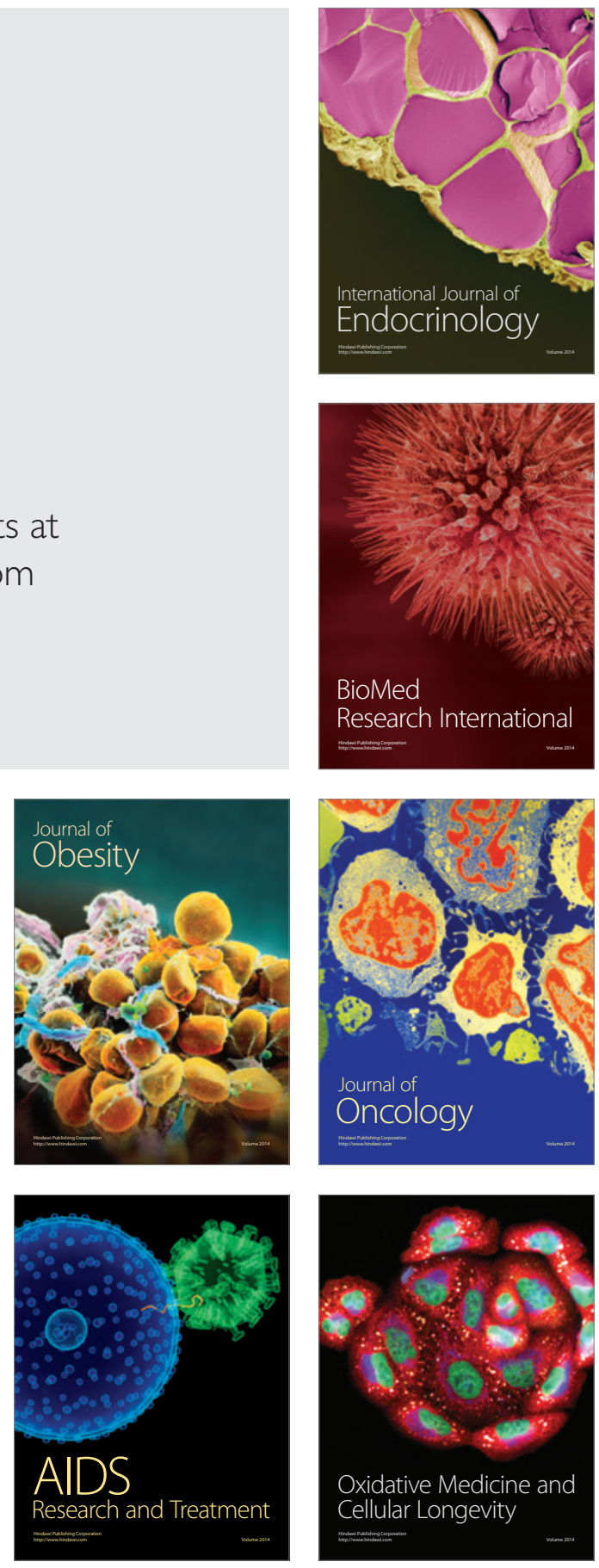